Revista de
Economila
Contemporâned

\title{
NEUTRALIDADE DO DÉFICIT PÚBLICO BRASILEIRO: EVIDÊNCIAS DA TEORIA DA EQUIVALÊNCIA RICARDIANA
}

\author{
Reisoli Bender Filho ${ }^{a}$ \\ ${ }^{\text {aD }}$ epartamento de Ciências Administrativas e do Programa de Pós-Graduação em Administração da \\ Universidade Federal de Santa Maria (UFSM).
}

Artigo recebido em 31/07/2012 e aprovado em 26/11/2014.

RESUMO: Testar a hipótese da Equivalência Ricardiana para a economia brasileira entre 1997 e 2011 consistiu no objetivo central do trabalho. Para isso, fez-se uso da especificação proposta por Modigliani e Sterling (1986), a qual testa a equivalência entre impostos e dívida pública por meio de uma função consumo. Além dessa especificação, estimou-se um modelo com déficit público padrão. Os resultados de ambos os modelos indicaram a não rejeição da Equivalência Ricardiana para a economia brasileira no período analisado. Entende-se, com isso, que, mantida a trajetória das despesas governamentais, os agentes econômicos tendem a não alterarem seu nível de consumo em função de mudanças na forma do financiamento daqueles gastos.

PALAVRAS-CHAVE: Teoria da equivalência Ricardiana; função consumo; economia brasileira.

CLASSIFICAÇÃO JEL: E60; C32. 


\section{NEUTRALITY BRAZILIAN GOVERNMENT DEFICIT: EVIDENCE OF THE THEORY RICARDIAN EQUIVALENCE}

ABSTRACT: To test the hypothesis of the Ricardian equivalence for the Brazilian economy between 1997 and 2011 was the central aim of the study. For that purpose, use has been made of the specification proposal made by Modigliani and Sterling (1986), which test for the equivalence of taxes and public debt by means of a consumption function. In accordance with that specification, a model with public debt default was estimated. Empirical results from both models indicate the non-rejection of the Ricardian Equivalence for the Brazilian economy. That is, if government spending is sustained, economic agents tend not to change their consumption level due to changes in the way of financing those expenditures.

KEYWORDS: Theory of Ricardian equivalence; consumption function; Brazilian economy.

\section{INTRODUÇÃO}

O aumento dos déficits e da dívida pública, nas últimas décadas, tem sido um problema recorrente tanto em economias desenvolvidas quanto em economias em desenvolvimento. Entretanto, a forma com que esse endividamento vem ocorrendo, por meio de intervenções governamentais cada vez mais frequentes, é foco de reiteradas discussões, as quais se baseiam nos efeitos econômicos associados a essas intervenções.

A forma de financiamento do déficit público comumente utilizado pelo governo centra-se em políticas fiscais expansionistas, por meio de alterações nos impostos e/ou nos gastos públicos. Todavia, essas alterações podem provocar efeitos reais sobre a economia conforme discute a teoria convencional da dívida pública ${ }^{1}$. Por outro lado, a teoria da Equivalência Ricardiana sugere que, para os agentes econômicos, o modo como o governo financia seus déficits (expansão da dívida pública ou aumento das alíquotas de impostos) é neutro.

Essa neutralidade estaria associada ao fato de que uma redução dos impostos no presente (elevação da dívida pública) significaria maiores impostos no futuro, de tal forma que os agentes econômicos manteriam inalterados seus padrões de consumo, $e$ a política fiscal não afetaria a trajetória das variáveis macroeconômicas reais.

Corroborando, Rezende (2010) enfatiza que, na hipótese da Equivalência Ricardiana, variáveis reais como consumo, acumulação de capital e atividade econômica não seriam afetadas em função de um aumento do endividamento público decorrente de mudanças presentes na trajetória dos gastos (reduções na carga tributária). Entretanto, esse aumento da dívida pública será irrelevante, dado que a menor tributação presente significa maiores impostos em um horizonte de tempo mais longo.

Essa proposição foi formalmente discutida por Barro (1974), ao evidenciar as condições para o endividamento público não serem entendidas pelos agentes como riqueza líquida. Nessa linha, Sachsida e Carlutti (2010) discutem que, quando ocorre um aumento do endividamento público, a redução da poupança do governo é compensada pelo aumento da poupança das famílias; logo, como a poupança doméstica não é alterada, a dívida pública passa a não ter efeitos reais sobre as variáveis econômicas. A suposição de que os agentes privados são indiferentes à maneira como o governo financia seus gastos remonta a Ricardo, no século XIX, mesmo não tendo ele desenvolvido as bases para uma discussão mais aprofundada sobre o tema.

Baseada na visão Keynesiana, sendo que no curto prazo, a dívida pública é um fator de estímulo à demanda agregada e de expansão da atividade econômica (Rezende, 2010). 
Rezende (2010) complementa, enfatizando que a hipótese sustentada pela Equivalência Ricardiana está centrada em três pressupostos, quais sejam: (i) os agentes econômicos tomam suas decisões no presente olhando para o futuro; (ii) o setor público defronta-se com uma restrição orçamentária, que intertemporalmente necessita ser atendida; e (iii) as famílias escolhem sua trajetória de consumo com base em sua renda permanente, não em sua renda disponível.

Contudo, a Equivalência Ricardiana encontra posições divergentes. No centro das questões estão as restrições de liquidez e os impostos distorcivos, aspectos que podem determinar que a hipótese da equivalência pode não ser mantida quando defrontada com situações reais, com base em avaliações empíricas.

Além desses, outro aspecto contrário à Equivalência Ricardiana, como salientado por Sachista e Carlutti (2010), está relacionado à entrada de novas famílias na economia, o que determinaria que o peso dos impostos futuros poderá ser repartido entre um maior número de agentes, possibilitando que parte do aumento da renda disponível seja empregada em consumo, contrariando assim o argumento da equivalência, que pressupõe que o aumento da renda seria poupado para satisfazer o aumento dos impostos futuros.

Nesta linha, buscando evidências sobre essa discussão, este trabalho procura contribuir para o debate propondo examinar a validade ou não da hipótese da Equivalência Ricardiana na economia brasileira dos anos 1997 a 2011, período no qual se evidencia um cenário de maior estabilidade econômica. Para isso, far-se-á uso da especificação de Modigliani e Sterling (1986), a qual testa essa hipótese a partir da construção de uma função consumo.

Além desta introdução, este trabalho está dividido em outras três seções. Na segunda seção é apresentada a metodologia do trabalho, enfatizando os modelos teórico e analítico, como também os testes utilizados para a estimação dos parâmetros. A terceira seção dá conta das evidências da Equivalência Ricardiana para a economia brasileira. E, por fim, na quarta seção, são delineadas as conclusões acerca do tema proposto.

\section{METODOLOGIA}

Para melhor desenvolvimento, essa seção está dividida em três partes. Na primeira, é caracterizado o modelo analítico com a apresentação do teste de especificação da função consumo proposto por Modigliani e Sterling (1986). A segunda traz o modelo econométrico e dos testes e hipóteses. E, na terceira parte, são expostas variáveis e as respectivas séries econômicas utilizadas na estimação do modelo.

\subsection{TESTE DE ESPECIFICAÇÃO DE MODIGLIANI E STERLING}

Diversas especificações para testar a equivalência entre a emissão de títulos públicos e impostos são encontradas na literatura. Com a ampliação do debate sobre o tema problematizado por Barro (1974), inúmeras proposições para testar a hipótese de Equivalência Ricardiana foram testadas, entre elas mencionam-se a de Buiter e Tobin (1979), a de Kormedi (1983), a de Modigliani e Sterling (1986), a de Feldstein e Elmendorf (1989) e a de Ball e Mankiw (1996).

Essas especificações propõem a verificação da Equivalência Ricardiana com base em diversas hipóteses, com grande maioria delas fazendo uso da estimação de uma função consumo, sendo que esta pode ser testada de duas maneiras: (i) comparando valores das variáveis referentes à dívida pública e à riqueza, que são variáveis de stock; e (ii) comparando os valores do rendimento com o déficit orçamentário, que são variáveis de fluxo, conforme discute Marinheiro (1996).

Dentro desse arcabouço, aqui é dado destaque à última proposição, a de Modigliani e Stearling (1986), a qual tem como característica a utilização conjunta de variáveis de stock e de fluxo. Formalmente, a proposição definida por esses autores parte da especificação em (1):

$$
C_{t}=a+b_{0} W_{t}+b_{1} D P_{t}+\sum_{i=1}^{L} c_{i}\left(Y_{t-i}-I L_{t-i}\right)+\sum_{i=1}^{L} d_{i} D O_{t-i}
$$

Em (1), $C$ é o consumo real per capita; $W$, a riqueza das famílias; $D P$, a dívida pública; $Y-T L$, o rendimento líquido (obtido a partir da diferença entre o produto agregado e os impostos líquidos); e $D O$, o déficit orçamentário; enquanto que $a, b, c$ e $d$ são os parâmetros do modelo. No modelo original de Modigliani e Sterling (1986), as expectativas são modeladas por meio da distribuição de valores passados.

Para o cálculo do déficit orçamentário, Modigliani e Sterling (1986) seguem a definição já utilizada por Buiter e Tobin (1979), como sendo a diferença entre o consumo público $(G)$ e os impostos líquidos $(I L)$, tal que $D O=G-I L$. Isso se deve ao fato de que, para a teoria da Equivalência Ricardiana, o conceito de rendimento é definido como sendo $Y-I L-D O=Y-G$. Conforme salienta Marinheiro (1996), essa relação fundamenta-se no fato de que, para o setor privado, os déficits são equivalentes aos impostos.

Na especificação de Modigliani e Sterling (1986), para que a hipótese da Equivalência Ricardiana seja confirmada, é necessário que as seguintes condições sejam atendidas: o coeficiente do déficit orçamentário deve ser necessariamente simétrico ao coeficiente do rendimento líquido, $\sum d_{i}=-\sum c_{i}$, e o coeficiente da dívida pública deve ser necessariamente simétrico ao coeficiente da riqueza, $b_{1}=b_{0}$. 
Utilizando a mesma forma funcional, adicionalmente é possível testar a validade da teoria do ciclo da vida (ver Modigliani, 1986), a qual propõe que o consumo depende da riqueza humana e não humana, sendo a primeira o valor atual do rendimento antecipado do trabalho após impostos. Dessa forma, o consumo privado estaria sujeito aos impostos presentes e futuros, como também às despesas governamentais. Para isso, os coeficientes do déficit orçamentário e da dívida pública deveriam ser nulos, tal que $\sum d_{i}=0$ e $b_{1}=0$.

\section{MODELO ECONOMÉTRICO}

Antes de apresentar o modelo analítico, são expostos os testes para identificação das caracteristícas das séries econômicas. Para esse objetivo, inicialmente descrevem-se os testes de estacionariedade (ou de raiz unitária). A existência de raiz unitária em séries temporais surge quando o polinômio autorregressivo tem uma raiz sobre o círculo unitário. Conforme Maia e Cribari-Neto (2006), uma raiz unitária nesse polinômio apresenta considerável interesse em aplicações, devido às suas importantes implicações para a modelagem, dado que sugere que a série segue um processo não estacionário integrado, no mínimo, de ordem um.

Todavia, existem diversos testes desenvolvidos com o propósito de examinar tal processo, dentre os quais se destacam Dickey-Fuller aumentado (ADF) e de Kwiatkowski, Phillips, Schmidt e Shin (KPSS). O primeiro e mais usualmente empregado na literatura examina a hipótese nula de que o processo autorregressivo possui uma raiz unitária, enquanto que o segundo tem na hipótese nula a ausência de raiz unitária (ou estacionariedade das séries)

Formalmente, o teste ADF é realizado a partir da estimação de uma autoregressão de $y_{t}$ em função de $y_{t-1}$ e dos termos defasados de $\Delta y_{t-1}$ por mínimos quadrados ordinários, como encontrado em Bueno (2008) e em Endres (2010), sendo que sua especificação segue a expressão em (2):

$$
\Delta y_{t}=\alpha+\beta t+\eta y_{t-1}+\sum_{i=1}^{p-1} \lambda_{i} \Delta y_{t-1}+\mu_{t}
$$

Em (2), $\lambda_{i}=-\sum_{j=i+1}^{p} \rho_{j}$ e tem como hipóteses:

$H_{0}: \rho=0$, presença de raiz unitária (a série é não estacionária); e

$H_{a}: \rho<0$, ausência de raiz unitária.

O KPSS é um teste alternativo ao ADF, sendo definido pelo procedimento de um teste de não estacionariedade contra a hipótese nula de estacionariedade, conforme se encontra em Greene (2008). Formalmente é expresso pela expressão em (3):

$$
\begin{aligned}
& y_{t}=\alpha+\beta t+\gamma \sum_{i=1}^{t} z_{i}+\varepsilon_{t} \\
& y_{t}=\alpha+\beta_{t}+\gamma Z_{t}+\varepsilon_{t}
\end{aligned}
$$

Em (3) há as seguintes hipóteses:

$H_{0}: \gamma=0$, série é estacionária; e

$H_{a}: \gamma \neq 0$, série é não estacionária.

Após identificação das propriedades das séries, na etapa seguinte, utilizando-se da especificação proposta por Modigliani e Sterling (1986), definiu-se o modelo econométrico estimado à economia brasileira para testar a hipótese de Equivalência Ricardiana:

$$
C P_{t}=\alpha_{0}+\gamma_{1} R I Q_{t}+\gamma_{2} D P_{t}+\sum_{i=1}^{L} \gamma_{3} R D L_{t}+\sum_{i=1}^{L} \gamma_{4} D O_{t}+v_{t}
$$

Em (4), $C P$ é o consumo privado real; $R I Q$, a riqueza das famílias; $D P$, a dívida pública; $R D L$, o rendimento disponível líquido; e $D O$ é o déficit orçamentário. O termo de erro aleatório é não correlacionado, tem média zero e variância $\sigma_{v}^{2}$. Todas as variáveis foram expressas em termos per capita, uma vez que se considera que as decisões são tomadas em nível microeconômico.

O rendimento disponível líquido foi obtido a partir da diferença entre o produto agregado e o valor total dos impostos (equivalente à carga tributária), descontadas as transferências governamentais, sendo a diferença entre o produto agregado e o $R D L$ os impostos líquidos. Para o cálculo do déficit orçamentário, seguiu-se a definição de Buiter e Tobin (1979) e utilizada por Modigliani e Sterling (1986), conforme apresentado anteriormente. Para a variável correspondente à riqueza, dado que não há uma série oficialmente calculada, foi utilizado o produto agregado filtrado pelo método de Hodrick e Prescott (HP) como proxy, conforme sugerido em Marinheiro (1996).

\section{VARIÁVEIS E DADOS}

As variáveis utilizadas na estimação da função consumo para a economia brasileira foram obtidas junto ao banco de dados do Instituto de Pesquisa Econômica Aplicada (IPEA), do Tesoutro Nacional (TN) e do Instituto Brasileiro de Geográfia e Estatística (IBGE). Todas elas estão expressas em milhões de reais, apresentam periodicidade trimestral e correspondem ao período entre o primeiro trimestre de 1997 e o segundo trimestre de 2011. A Tabela 1 apresenta detalhadamente as informações sobre o conjunto de variáveis usadas na estimação do modelo. 
Tabela 1 - Variáveis, séries e definições

\begin{tabular}{llll}
\hline Variável & Sigla & Série & Fonte \\
\hline Consumo privado & $C P$ & Consumo final das famílias & IPEA \\
Riqueza & $R I Q$ & PIB a preços de mercado filtrado - proxy & IPEA \\
Dívida Pública & $D P$ & Dívida líquida do setor público total & IPEA \\
Renda disponível líquida & $R D L$ & Calculada & TN" \\
Déficit orçamentário & $D O$ & Calculado & TN" \\
NFSP & $D E F$ & Necessidade de financiamento do setor público, no & IPEA \\
Indice de Preços & $I P C A$ & conceito primário, com desvalorização cambial & IPCA - variação percentual trimestral \\
População & $P O P$ & População residente & IPEA \\
\hline
\end{tabular}

Notas: (*) Para o primeiro e segundo trimestres de 2011 utilizou-se a série referente à população residente em $1^{\circ}$ de julho - estimativas. (**) Calculado com base nos dados do Tesouro Nacional.

Fonte: Elaboraçāo própria.

Ressalta-se que as variáveis foram deflacionadas pelo Índice de Preços ao Consumidor Amplo (IPCA), cuja base foi o segundo trimestre de 2011. Para a obtenção da população, como há disponibilidade de dados populacionais trimestrais, dividiu-se o total de habitantes de cada ano pelo número de trimestres, de forma a considerar um crescimento linear trimestral equivalente. Após a apresentação do modelo e das variáveis, na seção seguinte são discutidos os resultados do trabalho.

\section{ANÁLISE E DISCUSSÃO DOS RESULTADOS}

Inicialmente, com o objetivo de avaliar se as séries econômicas utilizadas seguem um processo estocástico estacionário, são apresentados os resultados dos testes de raiz unitária, ADF e KPSS, os quais se encontram na Tabela 2.

Tabela 2 - Resultados do teste de estacionariedade - Dickey-Fuller Aumentado (ADF)

\begin{tabular}{ccccccc}
\hline \multirow{2}{*}{ Variáveis } & \multicolumn{3}{c}{ Nível } & \multicolumn{3}{c}{ Primeira diferença } \\
\cline { 2 - 7 } & $\tau_{t}^{*}$ & $\mathbf{1} \%$ & $\mathbf{5 \%}$ & $\tau_{\mathrm{t}}^{*}$ & $\mathbf{1 \%}$ & $\mathbf{5 \%}$ \\
\hline$C P$ & $-0,615711$ & $-4,130526$ & $-3,492149$ & $-11,17030$ & $-4,130526$ & $-3,492149$ \\
$R I Q$ & $-0,305073$ & $-4,148465$ & $-3,500495$ & $-4,625861$ & $-4,165756$ & $-3,508508$ \\
$D P$ & $-1,933082$ & $-4,121303$ & $-3,487845$ & $-7,011105$ & $-4,124265$ & $-3,489228$ \\
$R D L$ & $-0,907251$ & $-4,137279$ & $-3,495295$ & $-4,450148$ & $-4,137279$ & $-3,495295$ \\
$D O$ & $-4,095049$ & $-4,137279$ & $-3,495295$ & $-3,417321$ & $-4,137279$ & $-3,495295$ \\
$D E F$ & $-2,724064$ & $-4,137279$ & $-3,495295$ & $-14,56362$ & $-4,133838$ & $-3,493692$ \\
\hline
\end{tabular}

Nota: (") $\tau_{t}$ com intercepto e com tendência. O critério de informação utilizado foi o de Schwars (SIC).

Fonte: Elaboração própria com base nos resultados da pesquisa.

Os resultados indicam que a hipótese nula $\left(H_{0}\right)$, de que a série testada é não estacionária (possui raíz unitária) em nível, é rejeitada para as seis variáveis quando con- siderado o nível de significância de $1 \%$. O mesmo ocorre quando se considera o níve de $5 \%$, com exceção da variável $D O$, que não apresentou raíz unitária a esse nível de significância. Todavia, quando testadas em primeira diferença, para todas as seis variáveis rejeitou-se a hipótese de não estacionariedade, sendo assim consideradas integradas de ordem zero $I(0)$ em diferença.

Buscando ratificar tais resultados, foi realizado o teste de Kwiatkowski, Phillips, Schmidt e Shin (KPSS), considerado um teste de análise confirmatória, uma vez que tem como hipótese nula a estacionariedade das séries, em contraposição aos testes usuais como o ADF. A finalidade da utilização de testes com hipóteses nulas opostas é suavizar o fato de que o teste ADF tem baixo poder, conforme discutido por Maddala e Kim (1998). Os resultados do teste KPSS encontram-se na Tabela 3.

Tabela 3 - Resultados do teste de estacionariedade - Kwaiatkowski, Phillips, Schmidt e Shin (KPSS)

\begin{tabular}{ccccccc}
\multicolumn{7}{c}{ Schmidt e Shin (KPSS) } \\
\hline \multirow{2}{*}{ Variáveis } & \multicolumn{7}{c}{ Nivel } & \multicolumn{3}{c}{ Primeira diferença } \\
\cline { 2 - 7 } & $L M^{*}$ & $\mathbf{1 \%}$ & $\mathbf{5 \%}$ & $L M^{*}$ & $\mathbf{1 \%}$ & $\mathbf{5 \%}$ \\
\hline$C P$ & 0,237801 & 0,216000 & 0,146000 & 0,124652 & 0,216000 & 0,146000 \\
$R I Q$ & 0,248032 & 0,216000 & 0,146000 & 0,155878 & 0,216000 & 0,146000 \\
$D P$ & 0,209705 & 0,216000 & 0,146000 & 0,092576 & 0,216000 & 0,146000 \\
$R D L$ & 0,264374 & 0,216000 & 0,146000 & 0,093462 & 0,216000 & 0,146000 \\
$D O$ & 0,264053 & 0,216000 & 0,146000 & 0,158250 & 0,216000 & 0,146000 \\
$D E F$ & 0,247917 & 0,216000 & 0,146000 & 0,099175 & 0,216000 & 0,146000 \\
\hline
\end{tabular}

Nota: (") $\tau_{t}$ com intercepto e com tendência. O critério de informação utilizado foi o de Newey-West Bandwidth. Fonte: Elaboração própria com base nos resultados da pesquisa.

Os resultados corroboram o teste $\mathrm{ADF}$, dado que se verifica que à exceção da variável $D P$, que não apresentou raíz unitária em nível, é rejeitada a hipótese nula $\left(H_{0}\right)$ para as demais variáveis, quando considerada a significância de $1 \%$, o que indica que as séries são não estacionárias. Porém, quando realizado o teste em diferença, eviden cia-se que, para as seis variáveis, não é possível rejeitar a hipótese de estacionariedade.

Após a verificação das propriedades estatistícas das séries econômicas, procedeu-se à aplicação empírica. Sendo as séries não estacionárias, a estimação do modelo somente poderá ser feita em nível caso as séries sejam cointegradas (apresentem uma relação de longo prazo). Assim sendo, foi realizado o teste de cointegração de Johansen, o qual indicou que as séries apresentam no máximo três vetores cointegrantes ao nível de 5\%, no caso da especificação de Modigliani e Sterling (Modelo 1) e, no máximo, quatro vetores cointegrantes ao mesmo nível de significância, no caso da especificação com déficit padrão (Modelo 2).

De forma complementar, testou-se a estacionariedade dos resíduos de ambas as regressões por meio dos testes ADF e KPSS, os quais indicaram a ausência de raiz unitária em nível, ratificando, assim, os resultados dos testes de cointegração e eliminando a 
possibilidade de as regressões apresentarem resultados espúrios. Os testes completos e suas respectivas estatísticas encontram-se em Anexo - Tabelas A1 e A2. Além disso, sendo os dados utilizados em periodicidade trimestral, fez-se necessária a correção da sazonalidade, a qual foi feita a partir do método de ajustamento sazonal de média móvel.

Como especificado, foram estimados dois modelos para testar a validade da hipótese de Equivalência Ricardiana para a economia brasileira. Em ambos, verificou-se a presença de correlação serial, a qual foi corrigida pela inclusão de termos defasados da variável dependente, sendo que os termos defasados foram definidos a partir do correlograma dos resíduos. Além dos testes de autocorrelação, foram realizados testes de normalidade e de heterocedasticidade, conforme Tabela 4. Para os dois modelos, os resíduos atenderam à pressuposição de normalidade, bem como não se verificou evidências de heterocedasticidade.

Tabela 4 - Testes de diagnóstico - normalidade, autocorrelação e heterocedasticidade - para os modelos 1 e 2 entre 1997 e 2011

\begin{tabular}{|c|c|c|c|}
\hline & $\begin{array}{l}\text { Normalidade } \\
\text { Teste Jarque-Bera }\end{array}$ & $\begin{array}{c}\text { Autocorrelação } \\
\text { Teste LM Breusch-Godfrey }\end{array}$ & $\begin{array}{l}\text { Heterocedasticidade } \\
\text { Teste de White }\end{array}$ \\
\hline \multicolumn{4}{|c|}{ Modelo 1} \\
\hline F estatístico & 0,601658 & $0,231299^{\varsigma} / 0,327254^{\varsigma \varsigma}$ & 1,358633 \\
\hline Probabilidade & 0,740204 & $0,919205 / 0,722680$ & 0,220778 \\
\hline \multicolumn{4}{|c|}{ Modelo 2} \\
\hline F estatístico & 0,304239 & $0,566801^{\varsigma} / 0,347420^{\varsigma \varsigma}$ & 1,526913 \\
\hline Probabilidade & 0,858886 & $0,571335 / 0,844359$ & 0,145714 \\
\hline
\end{tabular}

Nota: (s) 2 lags; (s) 4 lags

Fonte: Elaboração própria com base nos resultados da pesquisa.

Após a realização dos testes de diagnóstico, os resultados da especificação de Modigliani e Sterling (Modelo 1), bem como as estimativas do modelo alternativo, com déficit orçamentário padrão (Modelo 2), podem ser observados na Tabela 5. A partir do modelo 1, pode-se verificar uma relação negativa e estatisticamente significativa para o déficit orçamentário e para a dívida pública. Essa relação inversa sugere que elevações no financiamento das despesas governamentais por meio da expansão do endividamento tendem a retrair o consumo privado, o que ocorreria pela substituição do consumo de bens e serviços pela demanda de títulos públicos pelos agentes econômicos.

Por sua vez, o rendimento disponível líquido se relacionou positivamente com o consumo privado, porque, para cada aumento de R $\$ 1$ milhão, o consumo privado se elevou em cerca de R $\$ 275$ milhões, sendo estatisticamente significativo ao nível de 10\%; enquanto que a riqueza, apesar de apresentar um coeficiente positivo, como esperado, não indicou uma relação estatisticamente significativa. Essa não significância pode estar associada às limitações da utilização do produto filtrado como proxy da riqueza.
Tabela 5 - Resultados da estimação da função consumo para a economia brasileira entre 1997 e 2011: teste de equivalência usando a especificação de Modigliani e Sterling (1986) - variável dependente, consumo privado (CP)

\begin{tabular}{|c|c|c|}
\hline Variáveis & $\begin{array}{c}\text { Modigliani e Sterling } \\
\text { (Modelo 1) }\end{array}$ & $\begin{array}{c}\text { Com déficit padrão } \\
\text { (Modelo 2) }\end{array}$ \\
\hline Constante & $\begin{array}{c}0,00019 \\
(0,00037)\end{array}$ & $\begin{array}{l}-0,00029 \\
(0,00024)\end{array}$ \\
\hline$C P(-1)$ & $\begin{array}{l}0,27238^{*} \\
(0,14690)\end{array}$ & $\begin{array}{c}0,35555^{1 * *} \\
(0,12302)\end{array}$ \\
\hline$C P(-2)$ & $\begin{array}{l}-0,00583 \\
(0,10605)\end{array}$ & $\begin{array}{l}-0,12761 \\
(0,08979)\end{array}$ \\
\hline$C P(-4)$ & $\begin{array}{c}0,36511^{7 * *} \\
(0,11828)\end{array}$ & $\begin{array}{c}0,45186 * * * \\
(0,10278)\end{array}$ \\
\hline RIQ & $\begin{array}{c}0,04073 \\
(0,04436)\end{array}$ & $\begin{array}{l}0,08378^{*} \\
(0,05072)\end{array}$ \\
\hline$D P$ & $\begin{array}{c}-0,01860^{* * *} \\
(-0,01859)\end{array}$ & $\begin{array}{l}-0,01320^{*} \\
(0,00758)\end{array}$ \\
\hline$R D L$ & $\begin{array}{l}0,27509^{*} \\
(0,27509)\end{array}$ & $\begin{array}{c}0,20429^{* * *} \\
(0,05759)\end{array}$ \\
\hline$D O$ & $\begin{array}{l}-0,17923^{*} \\
(-0,17923)\end{array}$ & \\
\hline$D E F$ & & $\begin{array}{c}-0,20966^{* *} \\
(0,09382) \\
\end{array}$ \\
\hline$R 2$ & 0,987044 & 0,986767 \\
\hline R2 ajustado & 0,985028 & 0,984796 \\
\hline F estatistico & 489,7519 & 500,6781 \\
\hline$D W$ & 1,796729 & 2,005217 \\
\hline Teste Equivalência Ricardiana & & \\
\hline$D O=-R D L$ e $D P=-R I Q$ & 1,95624 & \\
\hline$D E F=-R D L$ e $D P=-R I Q$ & & 0,982233 \\
\hline$D O=-R D L$ & $3,67631^{*}$ & \\
\hline$D E F=-R D L$ & & 0,003644 \\
\hline$D P=-R I Q$ & 0,22764 & 1,941274 \\
\hline $\begin{array}{l}D O=0 \\
D P=0\end{array}$ & $\begin{array}{c}9,46244^{* * *} \\
2,66132^{*}\end{array}$ & \\
\hline $\begin{array}{c}D E F=0 \\
D P=0\end{array}$ & & $\begin{array}{l}4,994452^{\star *} \\
3,028375^{\star}\end{array}$ \\
\hline
\end{tabular}

Notas: Entre parênteses encontram-se os desvios-padrão. ${ }^{* * *)}$ significante ao nivel de $\left.1 \% ;{ }^{* *}\right)$ significante ao nível $5 \%$; (*) significante ao nivel $10 \%$

Fonte: Elaboração própria com base nos resultados da pesquisa.

Além do conjunto de variáveis analisadas, cabe enfatizar que o consumo privado corrente guarda uma relação importante com o consumo passado, pela significância estatistíca dos termos defasados, o que sugere que os indivíduos, em alguma medida determinam seu nível de consumo atual com base no consumo anterior, quando se considera que as condições econômicas permanecem constantes.

Contudo, apesar da evidente relação inversa entre o déficit público e o consumo privado, como verificado anteriormente, quando analisada a hipótese de neutralidade do déficit público testada pela simetria conjunta entre os coeficientes do déficit e do 
rendimento disponível $(D O=-R D L)$ e da dívida pública e da riqueza $(D P=-R I Q)$, os resultados conduzem a não rejeitar a hipótese de Equivalência Ricardiana ao nível de $5 \%$ de significância. Nesse contexto, poder-se-ia afirmar que a forma de financiamento das despesas governamentais, seja pela expansão da dívida pública ou pelo aumento dos impostos, não influenciou os padrões de consumo dos agentes econômicos na economia brasileira no período analisado. A partir disso, como observam Sachista e Carlutti (2010), alterações na composição do financiamento do governo tendem a não afetar o comportamento dos agentes.

Com o objetivo de examinar de forma mais específica as condições de equivalência, testaram-se as restrições separadamente. Assim, quando considerado o nível de significância de $5 \%$, chega-se a uma conclusão semelhante àquela obtida pelo teste de hipótese conjunto, de não rejeição da hipótese de equivalência. Porém, quando considerado o nível de significância de $10 \%$, os resultados não se mostraram robustos, uma vez que a simetria entre os coeficientes $(D P=-R I Q)$ não foi rejeitada, enquanto que se rejeita para a simetria entre os coeficientes $(D O=-R D L)$. Esse resultado pode indicar que o rendimento líquido obtido a partir do cômputo dos impostos e transferências, em alguma medida, poderá alterar a trajetória das variáveis macroeconômicas reais.

Complementarmente, quando testada a pressuposição da teoria do ciclo da vida (último conjunto de resultado da Tabela 5), a estimação da especificação de Modigliani e Sterling (1986) sugere que os coeficientes do déficit e da dívida pública não são nulos, o que indica a rejeição de tal hipótese para a economia brasileira no período entre 1997 e 2011.

Todavia, a medida de déficit orçamentário proposta por Buiter e Tobin (1979) encontra algumas limitações. Para Marinheiro (1996), essa forma de mensuração não considera uma parte importante das despesas governamentais, caso das transferências ao setor produtivo e das despesas de capital. Nesse sentido, para verificar a consistência dos resultados obtidos a partir da adequação da proposição de Modigliani e Sterling (1986) para a economia brasileira, foi utilizada uma segunda medida de déficit público, conceituada como déficit padrão.

Essa medida de déficit padrão foi definida com base nas necessidades de financiamento do setor público em seu conceito primário $(D E F)$, as quais são apuradas pelo Banco Central, sendo o déficit calculado com base na variação da dívida pública. Esse critério de apuração é denominado abaixo da linha ${ }^{2}$ define o déficit público conside-

2 Como as necessidades de financiamento do setor público no conceito primário excluem as necessidades de financiamento nominais, o pagamento de juros nominais é equivalente ao déficit primário - obtido a partir das receitas e despesas não financeiras - apurado pelo conceito acima da linha (Rezende, 2010). rando as suas formas de financiamento. As estimativas obtidas a partir da inclusão da $D E F$ na função consumo encontram-se na terceira coluna da Tabela 5, tendo sido designado de modelo com déficit padrão (ou Modelo 2). As demais variáveis estimadas nessa especificação seguiram as definições do Modelo 1.

Verifica-se que a direção dos sinais não sofreu alteração, com o déficit público sistematicamente negativo e estatisticamente significativo, o mesmo acontecendo com a dívida pública. Porém, observa-se que o $D E F$ apresentou uma relação mais fortemente negativa com o consumo quando comparada com aquela observada no Modelo 1. De outro lado, a renda disponível líquida e a riqueza foram positivas e significativas ao nível de $1 \%$ e $10 \%$, respectivamente, o que não havia sido encontrado quando estimada função consumo seguindo a proposta de Modigliani e Sterling (1986), no caso específico da variável relacionada a RIQ.

A Equivalência Ricardiana testada com a inclusão da variável $D E F$ indicou, tal como encontrado para a especificação de Modigliani e Sterling (1986), a não rejeição da hipótese de neutralidade do déficit público ao nível de significância de 5\%, tanto quando testada com as condições em conjunto quanto separadamente. Dessa forma, pode-se inferir favoravelmente a validade da teoria da Equivalência Ricardiana para a economia brasileira no período que se estende de 1997 a 2011 . De forma semelhante ao encontrado no Modelo 1, rejeitam-se as proposições da teoria do ciclo da vida.

Os resultados em direção à equivalência, aqui encontrados, estão em linha com os achados por Issler e Lima (2000) e por Sachsida e Teixeira (2000), os quais encontram resultados favoráveis à hipótese de Equivalência Ricardiana. Contudo, não há unanimidade nos resultados para a economia brasileira, uma vez que posições contrárias à validade dessa hipótese são encontradas nos trabalhos de Vieira (2005) e Sachsida e Carlutti (2010). Dessa forma, não é possível estabelecer uma conclusão definitiva a respeito desse tema para a economia brasileira, ao passo que devem ser considerados os aspectos particulares utilizados em cada situação.

\section{CONCLUSÕES}

A discussão proposta neste trabalho, de testar a validade da hipótese de neutralidade do déficit público para a economia brasileira a partir de uma determinada especificação, no caso, a proposição de Modigliani e Sterling (1986), foi desenvolvida na tentativa de subsidiar as discussões existentes na literatura econômica brasileira sobre este tema, como também a restrita gama de artigos dedicados ao assunto, o qual é de importância ímpar no suporte às decisões referente a políticas públicas. 
Os resultados, considerando tanto a proposição de Modigliani e Sterling (1986) quanto o modelo estimado com déficit padrão (Modelos 1 e 2), indicaram pela não rejeição da neutralidade do déficit público. No tocante a esses resultados, fica implícito que, mantida a evolução das despesas governamentais, os agentes econômicos tendem a não alterar sua trajetória de consumo em função de mudanças na forma do financiamento (mudanças nos impostos ou emissão de títulos públicos) destes gastos.

Uma explicação para a não rejeição dessa hipótese pode estar no contexto econômico de estabilidade encontrado na economia brasileira nos anos recentes, sobremaneira a partir do ano de 2000, o que possibilitaria aos agentes a maior certeza quanto à política governamental, bem como seus efeitos sobre a economia. Entretanto, como já encontrado em outros trabalhos, como o de Sachsida e Carlutti (2010), a rejeição ou não da hipótese de equivalência pode estar associada ao conjunto de variáveis utilizado, sendo que os modelos estimados limitam-se a captar a relação entre o consumo das famílias e a forma de gasto público considerado.

Neste sentido, os achados não geram condições suficientes para uma posição definitiva sobre $o$ assunto, ao passo que, para suavizar essas limitações, sugere-se a ampliação do período de análise e/ou o exame de outros períodos como forma de gerar resultados passíveis de comparação. Além disso, indica-se a utilização de outras especificações e modelagens, com hipóteses diferenciadas objetivando uma avaliação de caráter mais geral, e não somente particular, da condição de Equivalência Ricardiana na economia brasileira.

\section{REFERÊNCIAS}

BALL, L.; MANKIW, G. N. What do budget deficits do? NBER Working Paper, n. 5263, 1995.

BARRO, R. J. Are government bonds net wealth? Journal of Political Economy, v. 82, p.1095$1117,1974$.

BUENO, R. L. S. Econometria de séries temporais. São Paulo: Cengage Learning, 2008.

ENDERS, W. Applied Economics times series. 3 ed. Hoboken: Willey, 2010.

FELDSTEIN, M.; ELMENDORF, D. W. Taxes, budget deficits and consumer spending. NBER Working Paper, n. 2355, 1987

GREENE, W. H. Econometrics Analysis. 6 ed. New Jersey: Prentice Hall, 2010.

INSTITUTO BRASILEIRO DE ECONOMIA E ESTATÍSTICA (IBGE). Banco de dados - Sidra. Disponível em: $<$ http://www.sidra.ibge.gov.br/bda/popul/default.asp?z=t\&o=25\&i=P $>$. Acesso em: 18 jan. 2012.

INSTITUTO DE PESQUISA ECONÔMICA APLICADA (IPEA). IPEADATA. Disponível em: <http://www.ipeadata.gov.br/>. Acesso em: 12 nov. 2011.
ISSLER, J. V.; LIMA, L. R. Como se equilibra o orçamento do governo no Brasil: aumento de receitas ou corte de gastos? Pesquisa e Planejamento Econômico, v. 27, n. 3, p. 519-40, 1997.

MADDALA, G. S.; KIM, I. M. Unit roots, cointegration and structural change. Cambridge: Cambridge University Press, 1998.

MAIA, A. L. S.; CRIBARI-NETO, F. Dinâmica inflacionária brasileira: resultados de auto-regressão quantílica. Revista Brasileira de Economia, v. 60, n. 2, p. 153-165, 2006.

MARINHEIRO, C. J. F. O teorema da Equivalência Ricardiana: uma aplicação à economia portuguesa. Notas Económicas, v. 8, p. 42-55, 1996.

MODIGLIANI, F. Life cycle, individual thrift, and the wealth of nations. The American Economic Review, n. 76, p. 297-313, 1986.

MODIGLIANI, F.; STERLING, A. Government debt, government spending and private sector behavior: comment. American Economic Review, v. 76, n. 5, p. 1168-1179, 1986.

REZENDE, F. Finanças públicas. 2 ed. São Paulo: Atlas, 2010.

SACHSIDA, A.; CARLUCCI, F. N. Dívida pública afeta variáveis reais? um teste alternativo da Equivalência Ricardiana por meio de testes de superexogeneidade em séries simuladas. Texto para Discussão, IPEA, Brasília, n. 1505, 2010.

SACHSIDA, A.; TEIXEIRA, J. R. Ricardian equivalence, Lucas critic and exogeneity tests. Working Paper, Catholic University, 2000. Disponível em: <http://papers.ssrn.com/sol3/papers.cfm?abstract_id=293190>. Acesso em: 23 fev. 2012.

VIEIRA, B. F. Equivalência Ricardiana: evidência empírica para o caso do Brasil. Dissertação de Mestrado em Economia. Fundação Getúlio Vargas, Rio de Janeiro, 2005.

TESOURO NACIONAL (TN). Estatísticas. Disponível em: <http://www.tesouro.fazenda.gov. br/estatistica/index.asp>. Acesso em: 4 jan. 2012. 


\section{Anexos}

Tabela A1 - Resultados dos testes de cointegração (Teste de Johansen) para os modelos 1 e 2 entre 1997 e 2011

\begin{tabular}{|c|c|c|c|c|}
\hline $\begin{array}{c}\text { Hipótese } \\
\text { N. eq. coint. }\end{array}$ & Eigenvalue & $\begin{array}{c}\text { Estatística } \\
\text { Traço }\end{array}$ & $\begin{array}{c}\text { Valor crítico } \\
5 \%\end{array}$ & Probabilidade \\
\hline \multicolumn{5}{|c|}{ Modelo 1} \\
\hline None* & 0,963014 & 297,2903 & 88,80380 & 0,0000 \\
\hline At most $1^{*}$ & 0,575789 & 109,3493 & 63,87610 & 0,0000 \\
\hline At most $2^{*}$ & 0,415065 & 60,47035 & 42,91525 & 0,0004 \\
\hline At most $3^{*}$ & 0,277963 & 29,90388 & 25,87211 & 0,0149 \\
\hline At most 4 & 0,180409 & 11,34016 & 12,51798 & 0,0780 \\
\hline \multicolumn{5}{|c|}{ Modelo 2 } \\
\hline None* & 0,962945 & 318,6332 & 88,80380 & 0,0000 \\
\hline At most $1^{*}$ & 0,682337 & 130,7976 & 63,87610 & 0,0000 \\
\hline At most $2^{*}$ & 0,448168 & 65,43200 & 42,91525 & 0,0001 \\
\hline At most $3^{*}$ & 0,271614 & 31,54481 & 25,87211 & 0,0088 \\
\hline At most $4^{*}$ & 0,210609 & 13,48010 & 12,51798 & 0,0344 \\
\hline
\end{tabular}

Nota: $\left(^{*}\right)$ Denota a rejeição da hipótese nula ao nível de $5 \%$.

Fonte: Elaboração própria com base nos resultados da pesquisa.

Tabela A2 - Resultados dos testes de estacionariedade dos resíduos dos modelos 1 e 2 - ADF e KPSS

\begin{tabular}{ccccccccc}
\hline & \multicolumn{4}{c}{ ADF } & \multicolumn{3}{c}{ KPSS } \\
\cline { 2 - 9 } Variável & \multicolumn{2}{c}{ Modelo 1 } & \multicolumn{2}{c}{ Modelo 2 } & \multicolumn{2}{c}{ Modelo 1 } & \multicolumn{2}{c}{ Modelo 2 } \\
\cline { 2 - 10 } & $\tau_{\mu}{ }^{*}$ & $\mathbf{1 \%}$ & $\tau_{\mu}{ }^{*}$ & $\mathbf{1 \%}$ & $L M^{*}$ & $\mathbf{1 \%}$ & $L M^{*}$ & \multirow{1}{*}{$\mathbf{1 \%}$} \\
\hline$R E S$ & $-6,51416$ & $-3,56267$ & $-7,2406$ & $-3,55747$ & 0,08977 & 0,73900 & 0,09646 & 0,73900 \\
\hline
\end{tabular}

Nota: (*) $\tau_{\mu}$ com intercepto e sem tendência. O critério de informação utilizado na realização do teste ADF foi o de Schwars (SIC). O critério de informação utilizado na realização do teste KPSS foi o de Newey-West Bandwidth.

Fonte: Elaboração própria com base nos resultados da pesquisa. 